\title{
THE EFFECTS OF PREGANGLIONIC SYMPATHECTOMY ON IRIDIC CONDITIONING IN CAT
}

By

KARL ROBB GILDERSLEEVE

A DISSERTATION PRESENTED TO THE GRADUATE COUNCIL OF THE UNIVERSITY OF FLORIDA

IN PARTIAL FULFILLMENT OF THE REQUIREMENTS FOR THE DEGREE OF DOCTOR OF PHILOSOPHY

UNIVERSITY OF FLORIDA

1969 


\section{ACKNOWLEDGEMENTS}

I gratefully acknowledge the help of the following persons:

1. Nancy Gildersleeve whose aid in analyzing the data was the sine qua non of this undertaking.

2. Dr. F. A. King, whose criticisms of my ideas and the text improved the experiment and this dissertation in many ways. Thanks are also due to him for his steadfast support for six years through thick and thin.

3. Drs. H. S. Pennypacker, W. B. Webb, R. L. King and C. J. Vierck who are responsible for several clarifications of the original plans and of this paper itself.

4. Dr. Lamar Roberts and Dr. Jerald Bernstein who gave much time toward making my surgery successful.

5. Miss J. L. Berkowitz who typed the final copies on time despite the fact that she received the material from me at practically the last minute.

6. Mrs. Patricia Hopson who worked late hours to produce the fifteen figures scattered throughout this paper. She was under no such obligation to me.

7. Mrs. Sharon Buddington who always gave graciously of her time taking care of those many details that vex.

8. Drs. John Thornby and William Finley who gave advice and assistance on statistics. I am also indebted to Mr. Dennis Jowaisas who wrote a program for me, Mrs. Mary Carstensen who dealt with the computer for me, and Mary Jane Cochran who taught me to use the key punch. 
9. The Center for Neurobiological Sciences and the National Institutes of Mental Health which supported me and my family while this dissertation was prepared. 
TABLE OF CONTENTS

Page

Acknowledgements................... ii

List of Tables...................... v

List of Figures.................... vi

Introduction.................... 1

Method............................ 4

Results......................... 7

Discussion......................... 52

Summary......................... 54

Bibliography..................... 55

Biographical Sketch.................. 57 


\section{LIST OF TABLES}

Table

1. Number of CR's given by each cat in each session for all "CS+ and US" trials............................. 8

2. Number of CR's given by the normal eye of each cat in each session for "CS- alone" trials.................

3. Postoperative retention test day responding of the normal eye of each cat for the "CS+ alone" trials and the "CS- alone" trials............................... 10

4. Analysis of variance of pre- and postoperative interpupillary difference scores during the ISI for Cat 6 A31

5. Analys is of variance of pre- and postoperative interpupillary difference scores during the ISI for Cat 7E56...

6. Analysis of variance of pre- and postoperative interpupillary difference scores during the ISI for Cat 7F6

7. Analysis of variance of pre- and postoperative timecourse of the response of the normal eye during the ISI for Cat 6A31

8. Analys is of variance of pre- and postoperative timecourse of the response of the normal eye during the ISI for Cat 7E56.

9. Analysis of variance of pre- and postoperative timecourse of the response of the normal eye during the ISI for Cat 7F6. 


\section{LIST OF FIGURES}

Figure

Page

1. Preoperative time-course curve of iridic conditioned and unconditioned responses for Cat 6 A31 .............. 13

2. Preoperative time-course curve of iridic conditioned and unconditioned responses for Cat 7E56............. 15

3. Preoperative time-course curve of iridic conditioned and unconditioned responses for Cat $7 F 6 \ldots \ldots \ldots \ldots \ldots \ldots$

4. Postoperative time-course curve of iridic conditioned and unconditioned responses for Cat 6 A37 ............... 20

5. Postoperative time-course curve of iridic conditioned and unconditioned responses for Cat 7E56.............. 22

6. Postoperative time-course curve of iridic conditioned and unconditioned responses for Cat 7F6................... 24

7. Preoperative and postoperative time-course curves of interpupillary differences during the ISI for Cat 6 A31 .... 30

8. Preoperative and postoperative time-course curves of interpupillary differences during the ISI for Cat 7E56.... 32

9. Preoperative and postoperative time-course curves of interpupillary differences during the ISI for Cat 7F6...... 34

10. Preoperative differential curve of the iridic conditioned response for Cat 6 A31........................... 39

11. Preoperative differential curve of the iridic conditioned response for Cat 7E56.................. 41

12. Preoperative differential curve of the iridic

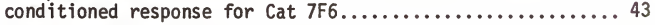

13. Postoperative differential curve of the iridic conditioned response for Cat 6 A31 ................... 45

14. Postoperative differential curve of the iridic conditioned response for Cat $7 E 56 \ldots \ldots \ldots \ldots \ldots \ldots . \ldots 47$

15. Postoperative differential curve of the iridic conditioned response for Cat $7 F 6 \ldots \ldots \ldots \ldots \ldots \ldots \ldots . \ldots . \ldots$ 


\section{INTRODUCTION}

The study of pupillomotor control has a long and controversial history. There have been two basic arguments: first, whether there is a dilator pupillae. Second, whether the sympathetic supply participates in phasic control of the iris during pupillary dilation or, alternatively, provides only a tonic background. Both of these basic questions have been answered in an extensive review of these historical controversies by Loewenfeld (1958). Existence of a functional dilator is now accepted. From the thorough studies of Lowenstein and Loewenfeld (1950) and the review mentioned earlier it can be concluded that responsibility for phasic dilation of the pupil is shared by the sympathetic and the parasympathetic nerve supplies. In response to stimuli such as shock or sudden noise there is, after unilateral sympathectomy, a marked reduction in magnitude of pupillary change on the sympathectomized side. Nevertheless the sympathectomized pupil is capable of one fifth the dilation of the normal pupil; and this degree of dilation must be accounted for in terms of parasympathetic inhibition (Loewenfeld, 1958).

This investigation represents an attempt to extend these findings in two ways: 1. Lowens tein and Loewenfeld studied responses to sensory stimuli which, in the normal iris of awake cats, follow a brief time course of one to three seconds of rapid dilation. The question arises as to whether the sympathectomized iris can follow the normal iris when the latter moves slowly in response to sensory stimuli. 
2. All Lowenstein and Loewenfeld studies involved unconditioned responses of the iris. The question arises as to what effects sympathectomy has on a learned response. A few studies have shed light on this problem. Affanni et al. (1962) and Zernicki and Osetowska (1963) worked with the iridic discriminative conditioned response (CR) of midpontine pretrigeminal transected cats, using hypothalamic shock as the unconditioned stimulus (US). Since the brainstem transection interrupts the pathways from the diencephalon to the spinal cord and sympathetic chain, this may be regarded as one type of sympathectomy. Their results indicate that a response is present after the operation, but in these studies there was no normal iris with which to compare the sympathectomized iris. The third study was that of Girden (1942) who found that sympathectomy abolished the CR. All data that he collected after sympathectomy were taken from heavily curarized dogs. After unilateral sympathectomy in one naive and three preoperatively conditioned dogs Girden noted "disturbance CR's" or hippus-like activity in response to the conditioned stimulus (CS) but he observed no normal CR's in the sympathectomized eye. The unoperated eye showed normal CR's. He concluded that the hippus was parasympathetic, and the normal response sympathetic, in origin.

Since iridic conditioning may be viewed as one element of a conditioned affective response to noxious stimulation, the question of the pattern of its innervation arises. Gellhorn and Loofbourow (1963, p.69) cited evidence from cardiovascular reactions suggesting that both 
sympathetic and parasympathetic sys tems are active during emotional responding but that the sympathetic effect dominates. The alternative view (Monnier, 1968, p. 190) holds that for any given effector there is selective activation of the sympathetic supply and inhibition of the parasympathetic supply. The present experiment allows a direct test of these two views. For the sympathectomized eye the first hypothesis would predict conditioned pupillary constriction and the second would predict pupillary dilation in response to the conditioning situation.

The intention of the present study was to describe the effects of peripheral sympathectomy on the discriminative iridic CR of normal waking cats. To this end the operative and pupillographic recording techniques of Lowenstein and Loewenfeld were combined with discrimination training. The advantages of this approach to the investigation of the effects of sympathectomy are:

1. It permits study of a slow iridic response,

2. It entails the study of a learned response,

3. It eliminates the possibility of contamination of the results by drug effects, and

4. It employs a surgical procedure that allows direct comparison of the normal and sympathectomized $C R$. 
METHOD

\section{Subjects.}

Three animals from a previous study (Gildersleeve, 1968) were used. Female cats 6A31, 7E56, and male cat, 7F6, had been trained to a high level of performance on iridic discrimination conditioning prior to the present investigation.

Apparatus and stimuli.

Apparatus from the earlier experiment was used and a detailed description is given elsewhere (Gildersleeve, 1968). Briefly, it consisted of a cat holder which firmly confined the animals so that they faced a stimulus panel for presentation of a positive CS (CS+ followed by shock) or a negative CS (CS- never followed by shock). Behind the stimulus panel was a concealed motion picture camera which recorded all trials on $16 \mathrm{~mm}$ film. The US was constant current shock adjusted throughout the experiment to maintain a consistent-amplitude UR.

Data were collected at $10 \mathrm{fps}$ on Kodak Tri-X reversal film. CS and US onset and offset were indicated on the movie record. A millimeter scale was also displayed in each frame of the record. The recorded image was enlarged six times and projected on a wall. A ruler calibrated to the size of the projected image of the millimeter scale was used to measure the pupils in each frame.

\section{Procedure.}

Trials were of three types: a) "CS+ alone" for 5 secs. constituted 
a test trial. b) "CS+ and US" trials were run with a 5 sec. CS period consisting of interstimulus interval (ISI) of $4 \mathrm{sec}$. followed by a $1 \mathrm{sec}$. US-on period. CS and US terminated simultaneously. c) "CS-alone" trials were also given. The term "CR" as used here refers to a pupillary change of $1 \mathrm{~mm}$ or more from the pre-CS value which occurred in the ISI or during the "CS on" period of "CS+ alone" trials and which lasted for at least $0.5 \mathrm{sec}$.

The procedure was divided into two phases. The preoperative phase consisted of the three days' discrimination training during which the cats reached training criterion in the final stage of the previous study. Criterion was attained when the iris responded to CS+ on no less than 80 percent of the "CS+ and US" trials over three consecutive sessions, and responded to CS- on no more than 20 percent of the "CS- alone" trials over these same three sessions. Cats were given ten trials of each type daily for those three days. The order of CSt and CS- was determined by a modified Gellermann series in which no session began or ended with a run of three CS+ or three CS- trials. In addition, two "CS+ alone" test trials were inserted into the series so that each test trial occurred in a different half of the daily session.

The postoperative phase consisted of two parts. The first part tested retention during one daily session in which ten "CS+ alone" trials and ten "CS- alone" trials were given in Gellermann series order six days following sympathectomy. The second part consisted of an exact replication of the entire preoperative phase. 
Surgery.

The cats were each subjected to unilateral preganglionic sympathectomy of the right eye. Under aseptic conditions and nembutal-atropine anes thesia, a midline incision was made over the larynx. The carotid sheath was exposed and incised. The vagosympathetic trunk was lifted onto a spatula and the two nerves were separated from each other with fine needles along two inches of their extent. The entire portion of the sympathetic trunk so separated was cut out to prevent regeneration. 


\section{RESULTS}

All results are based upon measurements from photographic pupillography.

Rate of conditioned responding in the normal iris.

Table 1 records the number of CR's attained by the normal (left) eye of each cat in each pre- and postoperative session for all "CS+ and US" trials.

Table 2 shows the number of CR's given in each pre- and postoperative session for all "CS-alone trials by the normal eye of each cat.

Table 3 shows the number of responses given by the normal eye for "CS+ alone" trials and "CS- alone" trials for each cat on the postoperative retention tes $t$ day.

In summary, the above results show clearly that each cat was highly trained to perform the discriminative iridic $C R$ before the operation and that neither the postoperative rest period nor the operation itself interfered with subsequent retention of the CR by the normal eye. Thus any response decrement shown by the sympathectomized iris was necessarily the result of the sympathectomy itself.

Time-course of the CR and UR of normal and sympathectomized iris.

The most convenient way to display the response decrement caused by the operation is to average across trials the time-course of iridic change before and after operation. This was done as follows: 
TABLE 1

NUMBER OF CR'S GIVEN BY EACH CAT

IN EACH SESSION FOR ALL "CS+ AND US" TRIALS

\begin{tabular}{rrrr}
\hline & 6 A31 & $7 E 56$ & $7 F 6$ \\
Preop & & & \\
Day 1 & 9 & 6 & 10 \\
Day 2 & 10 & 7 & 10 \\
Day 3 & 8 & 8 & 10 \\
Preop X & 9.0 & $7.0 *$ & 10.0 \\
\hline
\end{tabular}

Postop

\begin{tabular}{rccc} 
Day 1 & 6 & 10 & 10 \\
Day 2 & 10 & 6 & 10 \\
Day 3 & 9 & 10 & 9 \\
\hline Postop X & 8.3 & 8.7 & 9.7 \\
\hline
\end{tabular}

*This datum failed to reach criterion because there was a lapse in time between running a session and receipt of developed film. This forced the experimenter to base his decision as to when to operate an animal on his own estimates of pupil change. The film later showed that an error had been made. 
TABLE 2

NUMBER OF CR'S GIVEN BY THE NORMAL EYE

OF EACH CAT IN EACH SESSION FOR ALL "CS- ALONE" TRIALS

\begin{tabular}{cccc}
\hline & $6 \mathrm{~A} 31$ & $7 \mathrm{E} 56$ & $7 \mathrm{~F} 6$ \\
Preop & & & \\
Day 1 & 0 & 0 & 0 \\
Day 2 & 0 & 0 & 0 \\
Day 3 & 0 & 1 & 0 \\
\hline Preop X & 0.0 & 0.3 & 0.0 \\
\hline
\end{tabular}

\begin{tabular}{rccc} 
Postop & & & \\
Day 1 & 2 & 2 & 0 \\
Day 2 & 2 & 2 & 1 \\
Day 3 & 0 & 1 & 0 \\
\hline Postop X & 1.3 & 1.7 & 0.3 \\
\hline
\end{tabular}


TABLE 3

POSTOPERATIVE RETENTION TEST DAY RESPONDING OF THE

NORMAL EYE OF EACH CAT FOR THE "CS+ ALONE"

TRIALS AND THE "CS- ALONE" TRIALS

\begin{tabular}{cccc}
\hline & 6 A31 & 7E56 & 7F6 \\
CS+ alone & 5 & 9 & 7 \\
CS- alone & 1 & 0 & 0 \\
\hline
\end{tabular}


Test trials (CS+ alone) were excluded from the analysis since on these trials responses were identical to the $C R$ portion of the iridic response on "CS+ and US" trials. A11 "CS+ and US" trials in which the iridic response failed to reach criterion for a CR were excluded. Thus, all curves represent only responses on those "CS+ and US" trials in which the animal made a CR according to the previously described criterion. On each trial the three frames which immediately preceded the onset of the CS+ were examined and the average pupil size of the normal eye on those three frames was taken as an arbitrary zero point for both pupils. All other pupillary measures made for that trial were converted from their actual size in $\mathrm{mm}$ to deviation scores in $\mathrm{mm}$ from that arbitrary zero point. From every third frame of the photographic record, beginning wi th frame number 3 after the CS+ appeared, the deviation scores for the pupils of both eyes were recorded. This was continued throughout the trial until both CS and US were terminated. All deviation scores for the left and right eyes were summed and averaged for every third frame of all pre- and postoperative trials. These averages of pupillary size in $\mathrm{mm}$ of deviation from arbitrary zero were plotted along the ordinate against frame numbers as a time base on the abscissa. Figures 1, 2, and 3 are the preoperative curves for 6A31,7E56, and 7F6 respectively. It can be seen that the curve for the "to-be-sympathectomized" right eye describes a time-course which is almost exactly parallel to that of the normal left eye, but in each case is a little larger. This small anisocoria was the result of a slight difference in the test compartment 


\section{FIGURE 1}

PREOPERATIVE TIME-COURSE CURVE OF IRIDIC CONDITIONED AND UNCONDITIONED RESPONSES FOR CAT 6 A31 


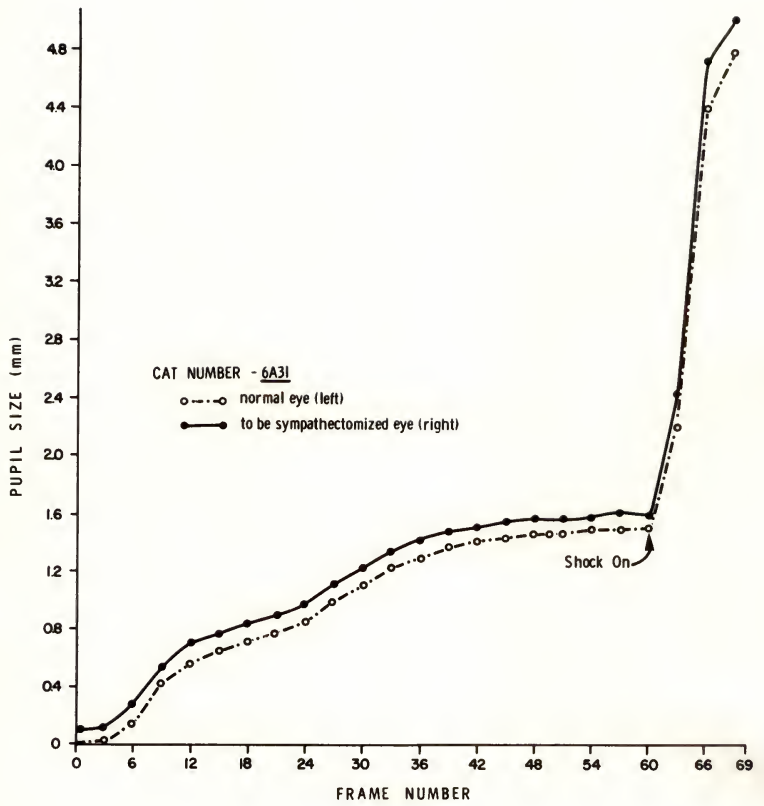




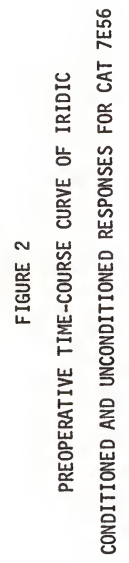




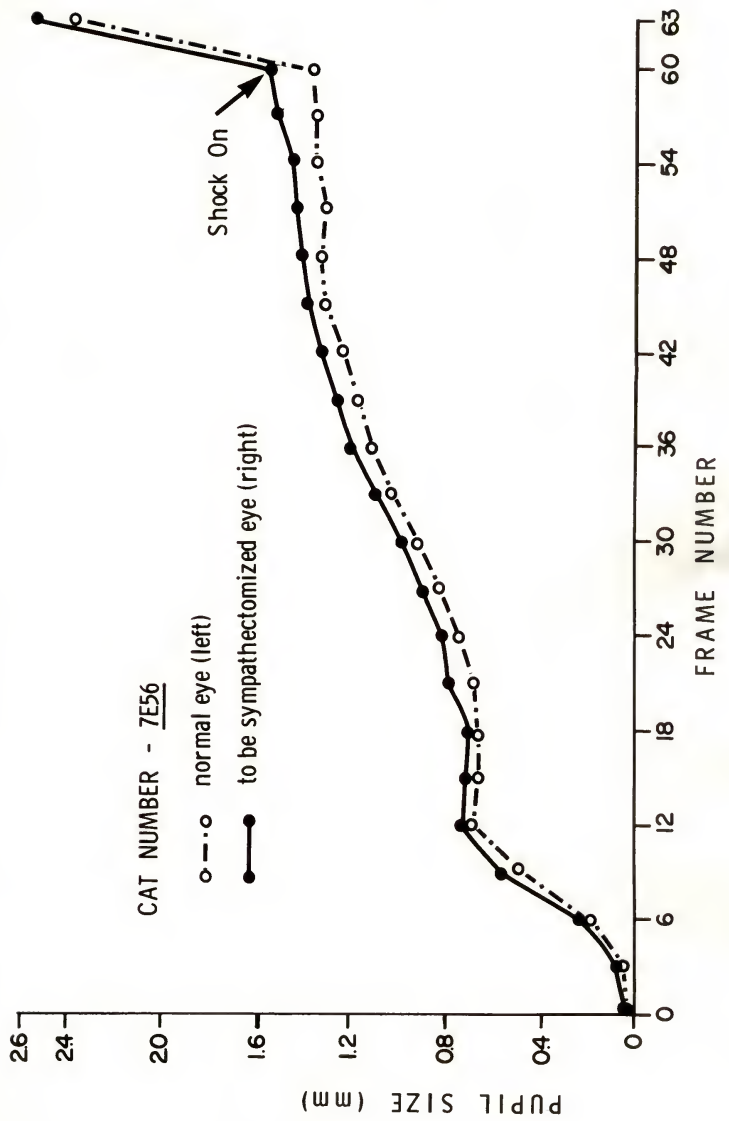




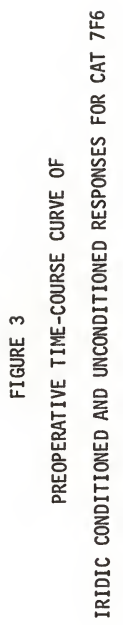




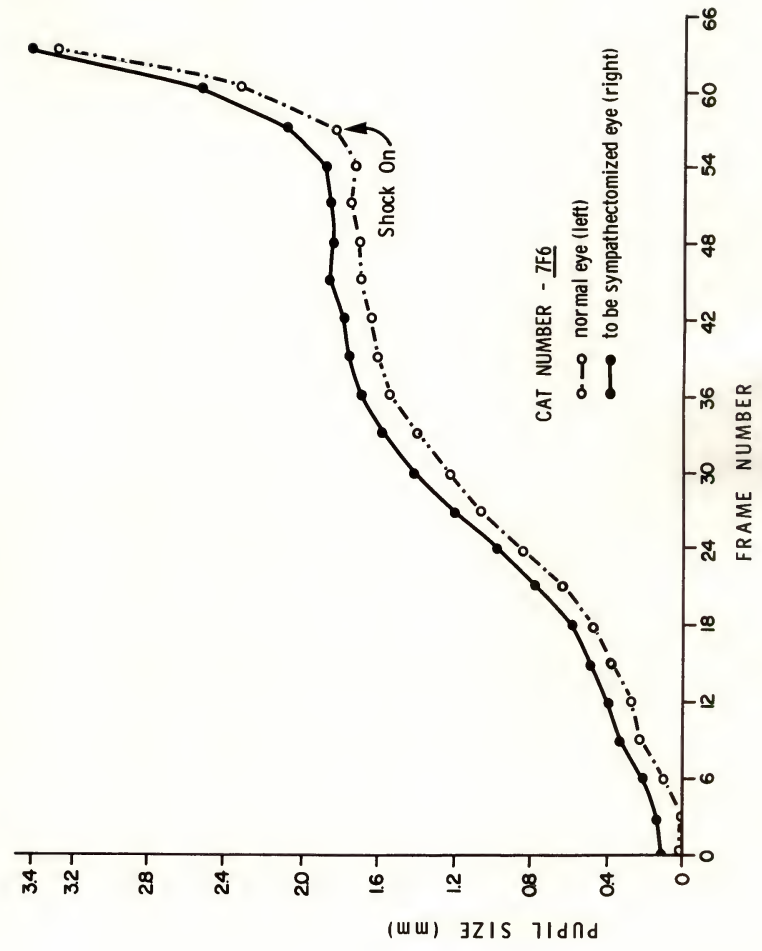


lighting for each eye. The curves show that the conditioned iridic response occurred in two fairly distinct phases. There was a rapid dilation immediately after onset of CSt. This probably represents an orienting response $(\mathrm{OR})$ to the CSt. Following this there was a slow steady dilation until shock was delivered.

The anisocoria was in a direction opposite to that produced by the sympathectomy, as can be seen from the postoperative time-course curves (Figures 4, 5, and 6). Since the size of the normal pupil at the beginning of each trial was taken as zero, the curve for the sympathectomized pupil contains exclusively negative values. Comparison of the normal and sympathectomized response curves reveals the basic findings of this study. First, the sympathectomized iris produced a CR in every cat. Second, the curves for the two eyes have roughly the same shape but are no longer parallel. In every case the curve of the normal iris has the steeper slope.

In order to substantiate the second conclusion statistically, analyses of variance were computed for each cat separately on the pre- and postoperative time-courses of interpupillary differences for each frame of each trial during the ISI. These were obtained by subtracting the deviation score for the normal pupil from the deviation score of the opposite pupil. If the time-course of these differences for the preoperative phase was different from that for the postoperative phase, then the interaction term of phases-by-frames should be significant. Tables 4, 5, and 6 show that this was the case for all cats. 
FIGURE 4

POSTOPERATIVE TIME-COURSE CURVE OF IRIDIC CONDITIONED AND UNCONDITIONED RESPONSES FOR CAT 6 A31 


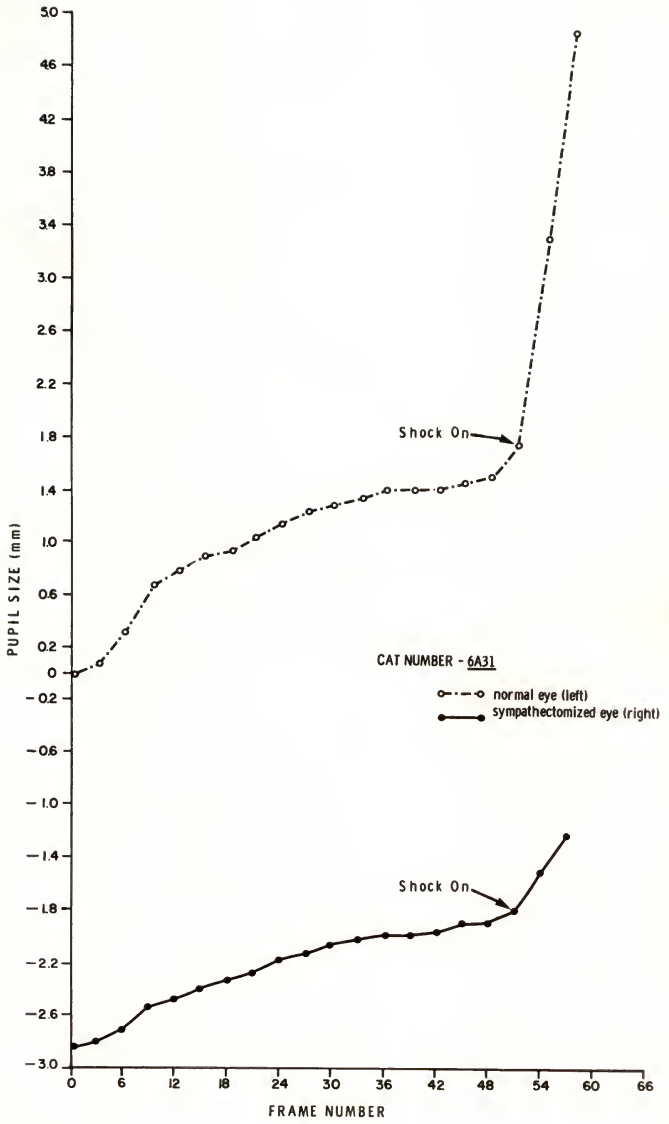




\section{FIGURE 5}

POSTOPERATIVE TIME-COURSE CURVE OF IRIDIC

CONDITIONED AND UNCONDITIONED RESPONSES FOR CAT 7E56 


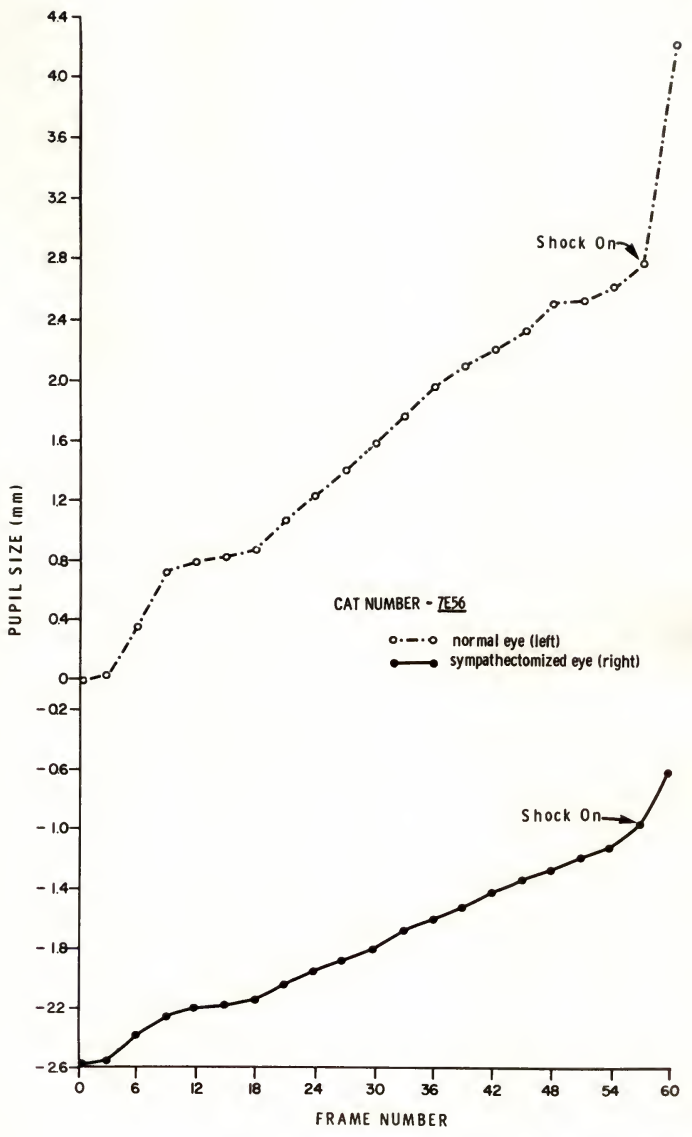


FIGURE 6

POSTOPERATIVE TIME-COURSE OF IRIDIC

CONDITIONED AND UNCONDITIONED RESPONSES FOR CAT 7F6 


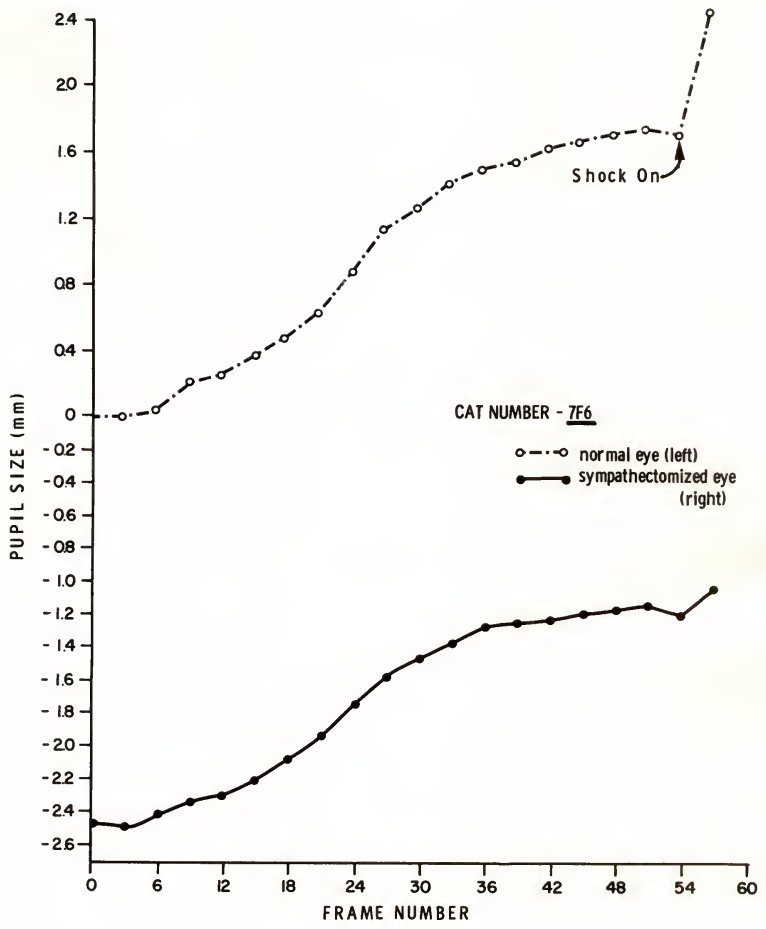


TABLE 4

ANALYSIS OF VARIANCE OF PRE- AND POSTOPERATIVE

INTERPUPILLARY DIFFERENCE SCORES DURING THE ISI FOR CAT 6 A31

\begin{tabular}{lrrrrr}
\hline \multicolumn{1}{c}{ Source } & df & Mean Square & F & p \\
\hline Phases & 1 & 243313.25 & 2084.97 & .01 \\
Trials wi thin Phases & 48 & 116.70 & & \\
& & & & \\
\hline Frames & 16 & 37.58 & 17.13 & .01 \\
Phases x Frames & 16 & 42.29 & 19.27 & .01 \\
Trials x Frames & & & & \\
within Phases & 768 & 2.19 & & \\
& & & & \\
\hline
\end{tabular}

Total

849 
TABLE 5

ANALYSIS OF VARIANCE OF PRE- AND POSTOPERATIVE

INTERPUPILLARY DIFFERENCE SCORES DURING THE ISI FOR CAT $7 E 56$

\begin{tabular}{lcccc}
\hline \multicolumn{1}{c}{ Source } & df & Mean Square & $F$ & $p$ \\
\hline Phases & 1 & 224013.87 & 3445.37 & .01 \\
Trials wi thin Phases & 40 & 55.02 & & \\
\hline Frames & 18 & 147.01 & 51.18 & .01 \\
Phases x Frames & 18 & 191.45 & 66.57 & .01 \\
Trials x Frames & & & & \\
wi thin Phases & 720 & 2.88 & & \\
\hline
\end{tabular}

Total 


\section{TABLE 6}

ANALYSIS OF VARIANCE OF PRE- AND POSTOPERATIVE

INTERPUPILLARY DIFFERENCE SCORES DURING THE ISI FOR CAT 7F6

\begin{tabular}{|c|c|c|c|c|}
\hline Source & df & Mean Square & $\mathrm{F}$ & $p$ \\
\hline Phases & 1 & 207349.50 & 3601.93 & .01 \\
\hline Trials within Phases & 56 & 57.57 & & \\
\hline Frames & 17 & 25.59 & 9.78 & .01 \\
\hline Phases $\times$ Frames & 17 & 44.86 & 17.14 & .01 \\
\hline \multicolumn{5}{|l|}{ Trials $\times$ Frames } \\
\hline within Phases & 952 & 2.62 & & \\
\hline
\end{tabular}


Figures 7, 8, and 9 show a plot of the average across all trials of pre- and postoperative time-course curves of interpupillary differences. The statistical analysis confirms the difference in slope of these two curves for each cat. The same analys is also confirms the difference in slope of the time-course curves of pupil size for the normal and sympathectomized eyes after the operation since the postoperative traces on Figures 7,8 , and 9 are linear transformations from postoperative timecourse curves of pupil size (Figures 4,5 , and 6).

Tables 7, 8, and 9 show the results of analyses of variance on the preoperative and postoperative time-course curves of pupil size for the normal eye alone. Since the phases-by-frames interaction was significant for $6 \mathrm{A31}$ and 7E56 in this analys is then it must be concluded that a small part of the difference between the postoperative time-course curves of pupil sizes was due to an increased responsiveness of the normal eye in two cases. However, the decreased responsiveness of the sympathectomized eye is by far the greater of the two effects as can be seen from Figures 4 and 5 . The difference between the two traces in Figures 4 , 5 , and 6 occurs regardless of rate of movement of the normal iris, but is most remarkable when the pupil opened quickly as it did during the OR to the CS, or immediately following delivery of the shock. Differential curves of the iridic CR and UR.

Another way to clarify the speed-dependent nature of the effects of sympathectomy is shown in the differential curves of the iridic CR before and after surgery (Figures 10, 11, 12, 13, 14 and 15). 
FIGURE 7

PREOPERATIVE AND POSTOPERATIVE TIME-COURSE CURVES

OF INTERPUPILLARY DIFFERENCES DURING THE ISI FOR CAT 6 A31 


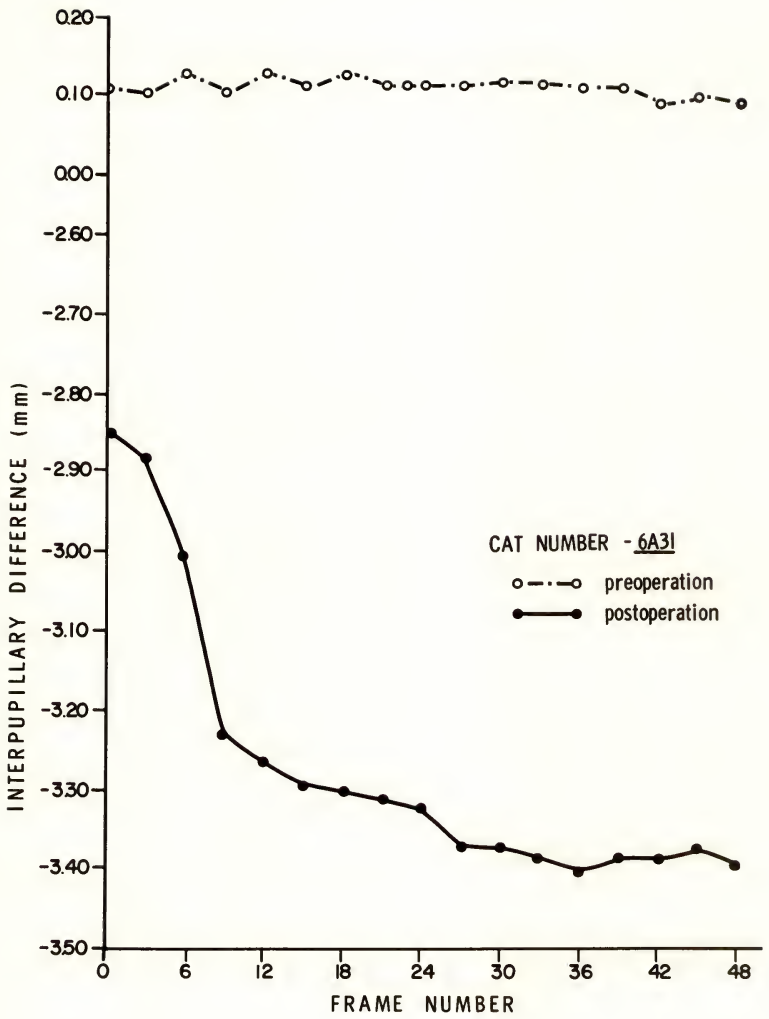


FIGURE 8

PREOPERATIVE AND POSTOPERATIVE TIME-COURSE CURVES

OF INTERPUPILLARY DIFFERENCES DURING THE ISI FOR CAT $7 E 56$ 


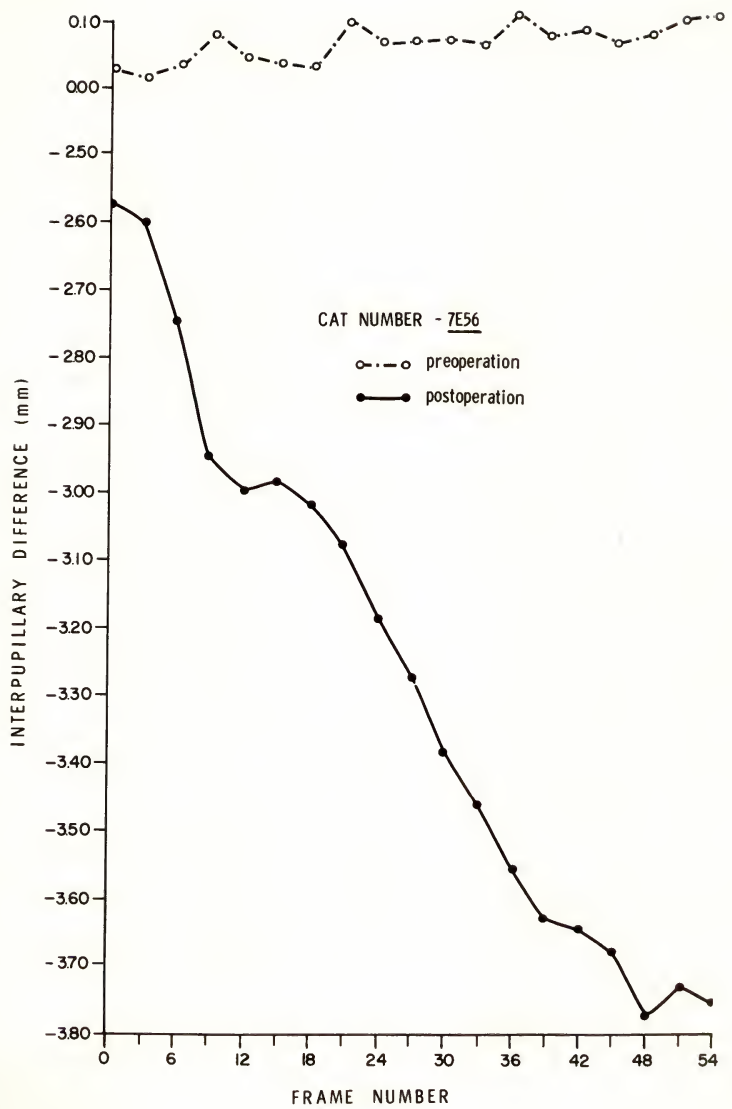


FIGURE 9

PREOPERATIVE AND POSTOPERATIVE TIME-COURSE CURVES

OF INTERPUPILLARY DIFFERENCES DURING THE ISI FOR CAT 7F6 


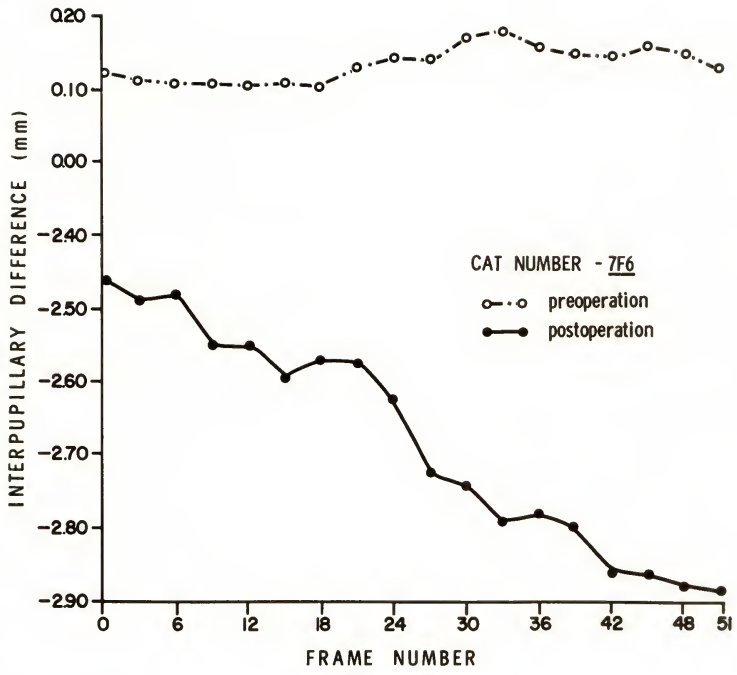




\section{TABLE 7}

ANALYSIS OF VARIANCE OF PRE- AND POSTOPERATIVE TIME-COURSE OF THE RESPONSE OF THE NORMAL EYE DURING THE ISI FOR CAT 6 A3!

\begin{tabular}{lrrrr}
\hline \multicolumn{1}{c}{ Source } & df & Mean Square & $F$ & $p$ \\
\hline Phases & 1 & 826.13 & 6.19 & .01 \\
Trials wi thin Phases & 48 & 133.37 & & \\
\hline Frames & 16 & 1195.10 & 220.18 & .01 \\
Phases $x$ Frames & 16 & 17.41 & 3.21 & .01 \\
Trials x Frames & & & & \\
within Phases & 768 & 5.43 & & \\
\hline
\end{tabular}

Total

849 
TABLE 8

ANALYSIS OF VARIANCE OF PRE- AND POSTOPERATIVE

TIME-COURSE OF THE RESPONSE OF THE NORMAL EYE DURING THE ISI FOR CAT 7E56

\begin{tabular}{lcccc}
\hline \multicolumn{1}{c}{ Source } & df & Mean Square & $F$ & $p$ \\
\hline Phases & 1 & 8594.89 & 36.12 & .01 \\
Trials wi thin Phases & 40 & 237.93 & & \\
& & & & \\
\hline Frames & 18 & 1769.93 & 155.47 & .01 \\
Phases x Frames & 18 & 222.38 & & \\
Trials x Frames & & & & \\
within Phases & 720 & 11.38 & & \\
& & & & \\
\hline Total & 797 & &
\end{tabular}


TABLE 9

ANALYSIS OF VARIANCE OF PRE- AND POSTOPERATIVE

TIME-COURSE OF THE RESPONSE OF THE NORMAL EYE DURING THE ISI FOR CAT $7 F 6$

\begin{tabular}{lrrrr}
\hline \multicolumn{1}{c}{ Source } & df & Mean Square & $F$ & $p$ \\
\hline Phases & 1 & 8.11 & 0.00 & NS \\
Trials wi thin Phases & 56 & 259.83 & & \\
\hline Frames & 17 & 2557.58 & 209.47 & .01 \\
Phases x Frames & 17 & 2.39 & 0.20 & NS \\
Trials x Frames & & & & \\
wi thin Phases & 952 & 12.21 & & \\
\hline Total & 1043 & & & \\
\hline
\end{tabular}


FIGURE 10

PREOPERATIVE DIFFERENTIAL CURVE OF THE IRIDIC CONDITIONED RESPONSE FOR CAT 6 A31 


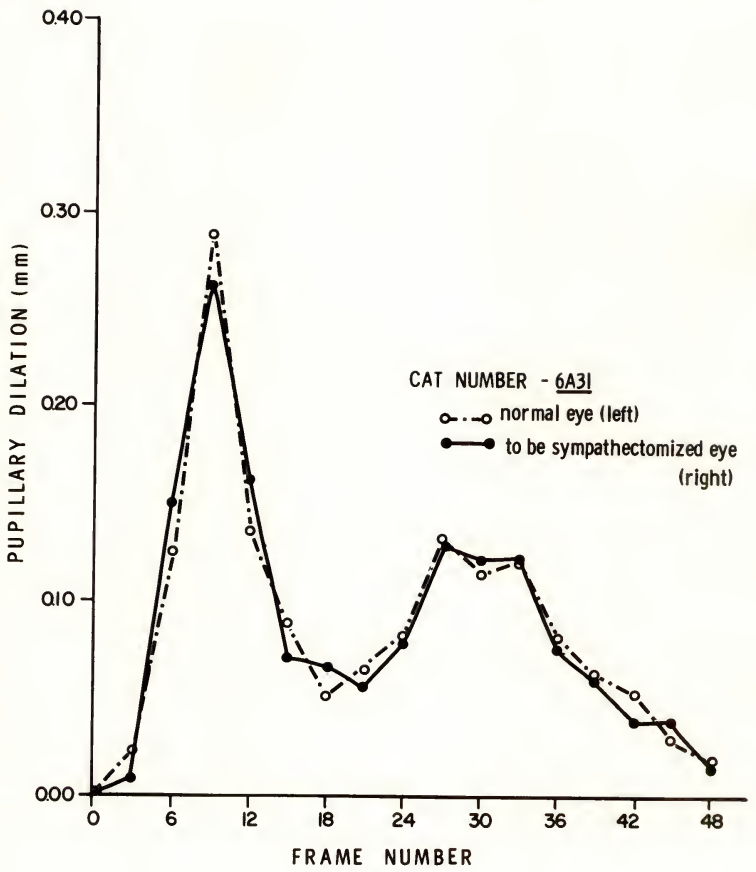


FIGURE 11

PREOPERATIVE DIFFERENTIAL CURVE OF THE IRIDIC CONDITIONED RESPONSE FOR CAT 7E56 


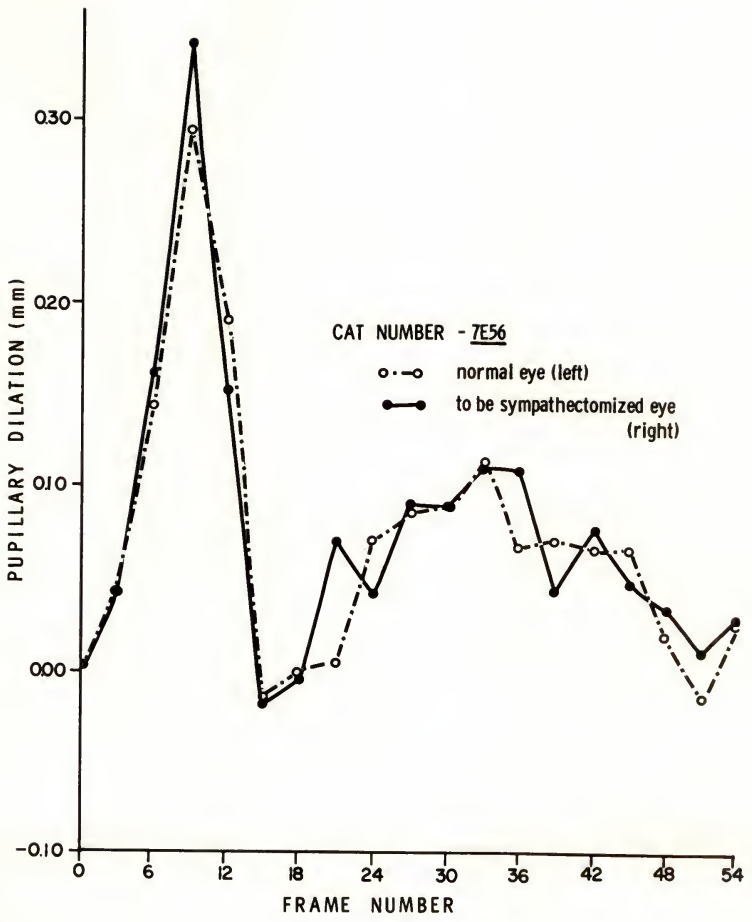


FIGURE 12

PREOPERATIVE DIFFERENTIAL CURVE OF THE IRIDIC CONDITIONED RESPONSE FOR CAT 7F6 


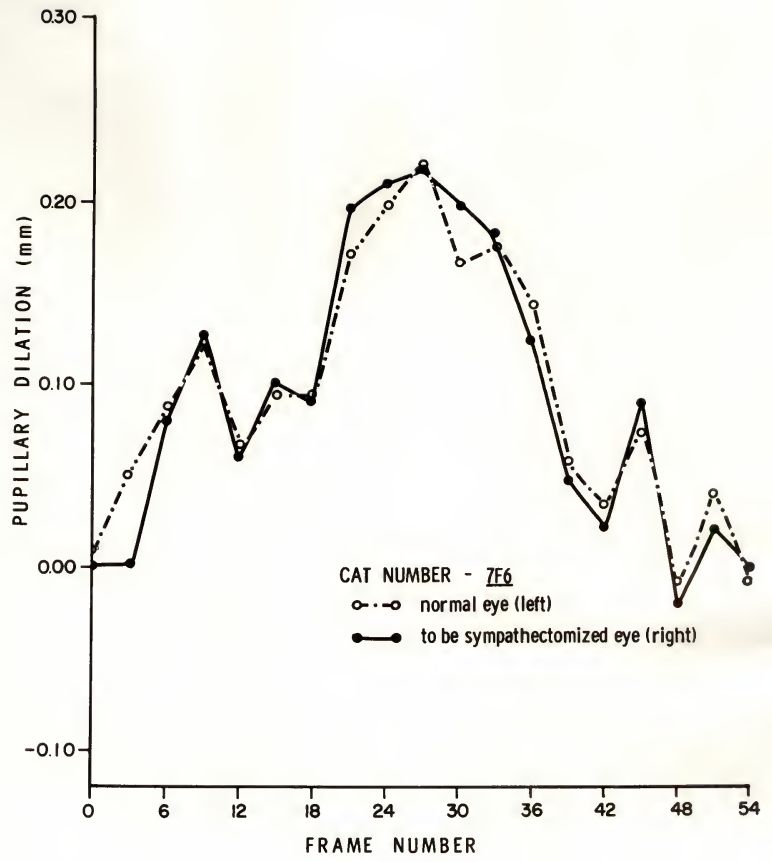


FIGURE 13

POSTOPERATIVE DIFFERENTIAL CURVE OF THE IRIDIC CONDITIONED RESPONSE FOR CAT 6A31 


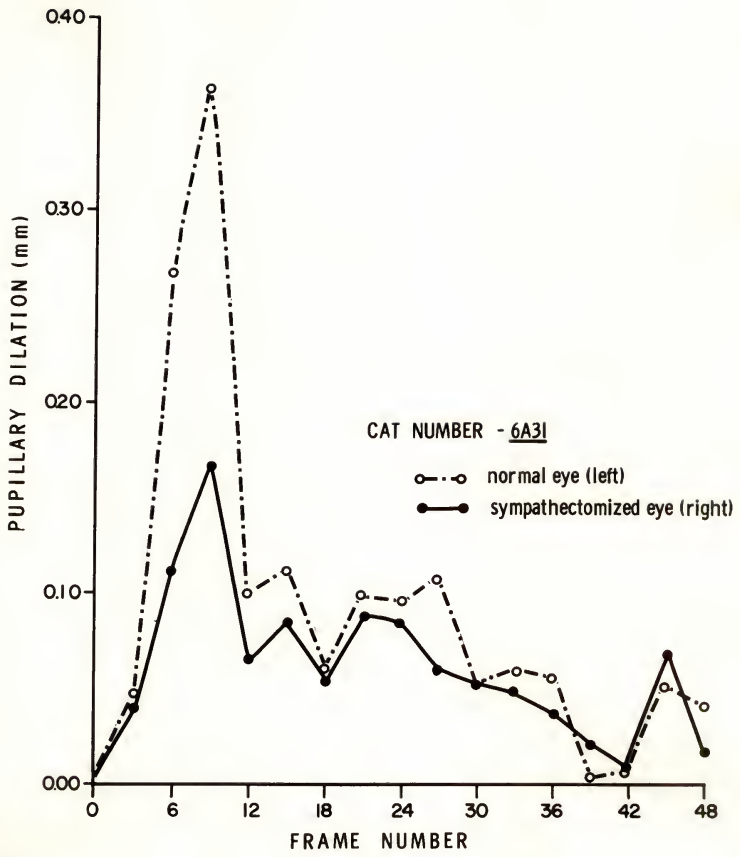


FIGURE 14

POSTOPERATIVE DIFFERENTIAL CURVE OF THE IRIDIC CONDITIONED RESPONSE FOR CAT 7E56 


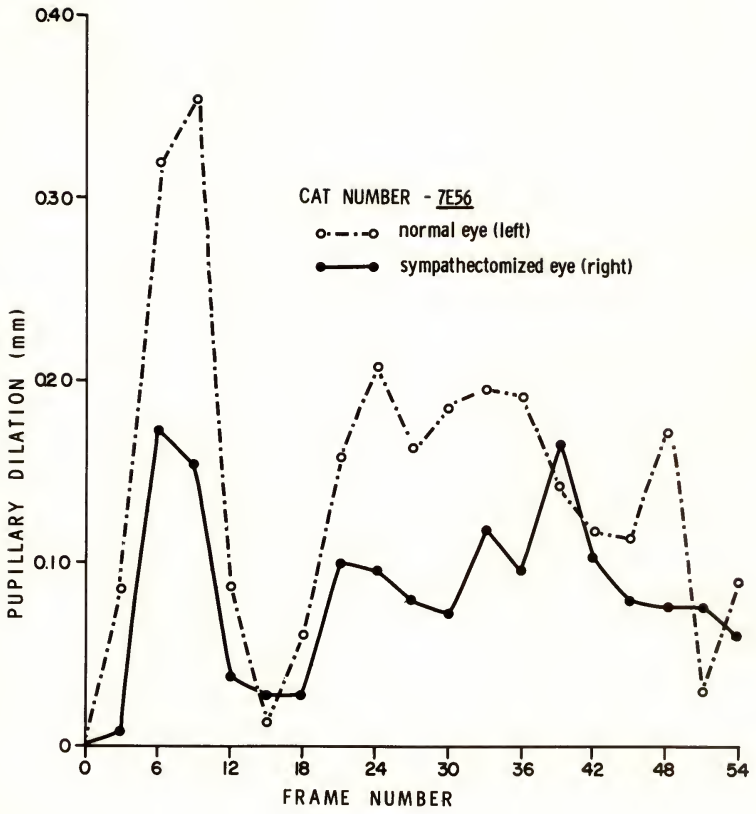


FIGURE 15

POSTOPERATIVE DIFFERENTIAL CURVE OF THE IRIDIC CONDITIONED RESPONSE FOR CAT 7F6 


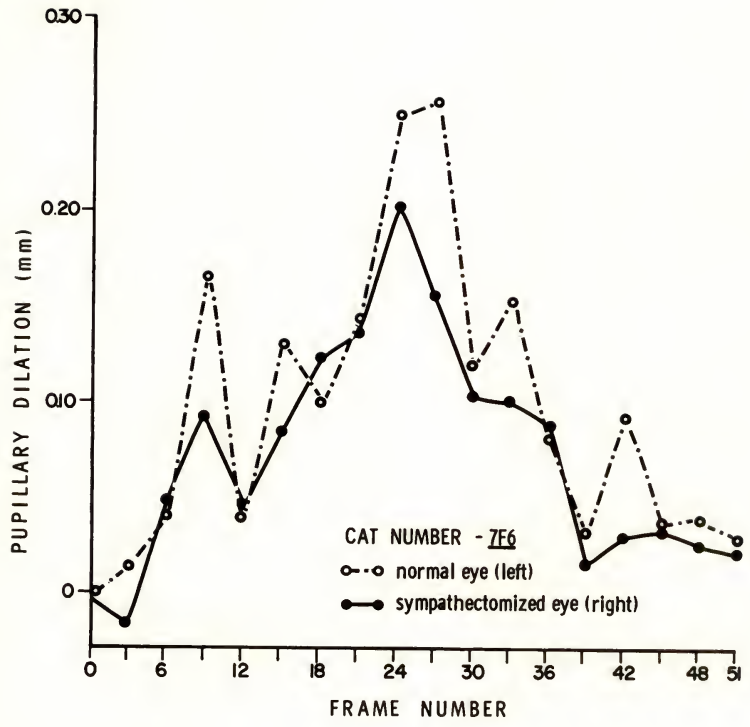


These were obtained from the time-course curves as follows: The amount of dilation occurring between successive measured frames was obtained by subtracting the deviation score of the previous measured frame from the deviation score of the frame in question. These differences of deviation scores were then plotted for each eye, thus giving a close approximation of the differential of the time-course curves. This constitutes a digital speedplot of the iridic motions. These curves show that preoperatively there were virtually no differences in speed of the two irises. The postoperative curves, however, show clearly that if the normal pupil changed slowly then the sympathectomized eye followed fairly wel1; but when the normal iris moved quickly then the sympathectomized iris followed poorly. Consensual darkness reflex.

In 1960 Guth and Bailey described a reflex of the normally innervated iris following sympathectomy of the opposite eye. They reasoned that since the operation reduces the amount of light admitted to the retina of the sympathectomized eye, the normally innervated pupil should dilate consensually. They therefore compared the size of the normal pupil before and after the operation and showed that indeed it was significantly larger postoperatively. In the present study comparable data are available from the three frames used to establish the arbitrary zero point for each trial, pre- and postoperatively. A statistical comparison of the preand postoperative means of these measures was made. Student's $t$ (8.888) for the difference between the preoperative mean of $3.013 \mathrm{~mm}$ and the postoperative mean of $4.178 \mathrm{~mm}$ was significant beyond the 1 percent 
level of confidence with $210 \mathrm{df}$.

The statistical comparison of the time-course curves for the normal eye (Tables 7, 8, and 9) showed that an increase in speed of response occurred after the operation in two cats 7E56 and 6A31. This effect could be due to either a phasic consensual reflex, or to the continuation of training. The latter is the more likely alternative. 7E56 showed the poorest rate of responding and she also showed the most improvement in speed of response after the operation. 6A31 occupies an intermediate position on both continua. 7F6, which had the highest conditioning scores, and therefore had the least room for improvement, showed no increased speed of response at all. It can be concluded from his data alone that a phasic consensual reflex is neither a necessary nor a reliable consequence of sympathectomy. 


\section{DISCUSSION}

From this study it can be concluded that slow responses of the cat iris, including a CR with a long time-course, can be produced by a sympathectomized iris, but with great impairment. The present investigation also shows that as the speed of the normal iris increases, the weakness of the sympathectomized iris becomes increasingly apparent. When the normal pupil dilates faster than $0.4 \mathrm{~mm}$ per second the sympathectomized pupil begins to lag. It can also be concluded that sympathectomy produces a tonic consensual darkness reflex which increases the difference in size of the two pupils when the irises are at rest, but probably does not change the phasic activity of the normal iris. Except for 7E56, the time-course curves of the normal pupil before and after the operation are quite similar. Such differences as do exist can probably be explained by improved performance. In any case, the hypothes is that there is a phasic consensual darkness reflex which potentiates conditioned responding after sympathectomy would still have to account for the fact that 7F6 showed no such potentiation.

These findings extend those of Lowenstein and Loewenfeld whose work on slow iridic responses after sympathectomy was confined to such cases as pupillary changes immediately preceding death or spontaneous pupillary activity immediately prior to waking. The present investigation involved waking cats which were normal in every respect except for their sympathectomies. The CR which they performed is probably more typical 
of the variety of slow responses which the iris normally makes.

The present study is the first to apply the precise pupillographic technique of Lowenstein and Loewenfeld to the investigation of CR's. The conflict between the results of Girden and those of Zernicki and Osetowska and Affanni et al. might be more easily resolved if all these authors had reported complete pupillographic data. It is clear from the present study that the CR survives sympathectomy in the otherwise normal uncurarized cat, a finding which is contrary to that of Girden, but which agrees with the reports of Zernicki and Osetowska and Affanni et al. However, the presence of a normally innervated iris in this experiment allows the additional conclusion that part of the response is carried by the sympathetic supply. It is not possible to conclude this from brainstem transection studies which effectively sympathectomized both eyes and in which no preoperative data were cited.

The present findings also show that insofar as the iris muscle is concerned, conditioned emotional responding proceeds by sympathetic activation and parasympathetic inhibition. This is not consistent with the findings cited by Gellhorn and Loofbourow (1963) for the cardiovascular organs indicating simultaneous activation of both supplies. 


\section{SUMMARY}

The performance of three cats, highly trained in a classical iridic discrimination situation, was recorded before and after sympathectomy of one iris. The results showed that the sympathectomized iris was able to follow the response of the normal iris only when the latter was moving slowly. The operation also induced a tonic consensual darkness reflex in the normal eye. 


\section{BIBLIOGRAPHY}

Affanni, J., Marchiafava, P., and Zernicki, B. Conditioning in the midpontine pretrigeminal cat. Archives Italiennes de Biologie, 1962, $100,305-310$.

Gellhorn, E., and Loofbourow, G. Emotions and Emotional Disorders. New York: Harper and Row, 1963.

Gildersleeve, K. Discrimination and Retention of the Iridic Conditioned Response in Cat. Unpublished Master's Thesis. University of Florida, 1968.

Girden, E. The dissociation of pupillary conditioned reflexes under erythroidine and curare. Journal of Experimental Psychology, 1942, 31, 322-332.

Guth, L., and Bailey, C. Effects of unilateral sympathectomy on the contralateral pupil of the cat. Experimental Neurology, 1960, 2 , 90-96.

Loewenfeld, I. Mechanisms of reflex dilatation of the pupil. Documenta Ophthalmalogica, 1958, 12, 185-448. 
Lowenstein, 0., and Loewenfeld, I. Role of sympathetic and parasympathetic systems in reflex dilatation of the pupil. Archives of Neurology and Psychiatry, 1950, 64, 313-340.

Monnier, M. Functions of the Nervous System. Volume 1. Amsterdam: Elsevier, 1968.

Zernicki, B., and Osetowska, E. Conditioning and differentiation in the chronic midpontine pretrigeminal cat. Acta Biologica Experimentalis, $1963,23,25-32$. 


\section{BIOGRAPHICAL SKETCH}

Karl Robb Gildersleeve was born 11 July, 1938, at Bellevue, Pennsylvania. In June, 1956, he graduated from Bel levue High School. In June, 1960, he received the degree of Bachelor of Arts with a major in Psychology from the College of Wooster. From then until 5 october, 1961, he worked for the Department of Public Assistance of the state of Pennsylvania as a caseworker. He entered service in the United States Army, working for Human Resources Research Office as a psychological research assistant. Following release from active duty on 26 August, 1963, he entered graduate school at the University of Florida. He worked as a graduate research assistant in the Division of Neurosurgery, College of Medicine, until July, 1965. Since then he has held a Graduate Fellowship from the Center for Neurobiological Sciences. He received a Master of Arts degree with major in Psychology from the University of Florida in December, 1968.

Karl Robb Gildersleeve is married to the former Nancy Boone and is the father of one child, Susan Katherine. 
This dissertation was prepared under the direction of the chairman of the candidate's supervisory committee and has been approved by all members of that committee. It was submitted to the Dean of the College of Arts and Sciences and to the Graduate Council, and was approved as partial fulfillment of the requirements for the degree of Doctor of Philosophy.

December, 1969

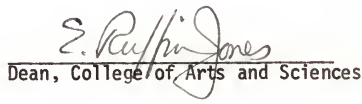

\section{Dean, Graduate School}

Supervisory committee:

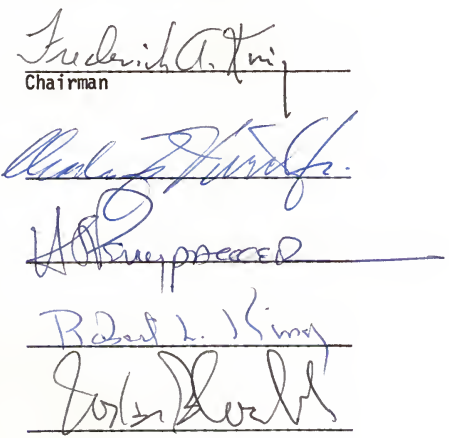

